\title{
VIOLÊNCIA COM PROFISSIONAIS DA ATENÇÃO BÁSICA: ESTUDO NO INTERIOR DA AMAZÔNIA BRASILEIRA*
}

\author{
Beatriz Gomes Molinos ${ }^{1}$, Elza Berger Salema Coelho², Rodrigo Otavio Moretti Pires ${ }^{3}$, Sheila Rubia Lindner ${ }^{4}$
}

\begin{abstract}
RESUMO: Estudo exploratório-descritivo tenho por objetivo identificar episódios de violência com profissionais da Estratégia Saúde da Família do interior do Estado do Amazonas e sua percepção sobre as condições de segurança e prevenção da violência no trabalho. Foi aplicado um questionário, autoaplicável, semiestruturado e adaptado do Survey of Violence in the Workplace for Health Care Workers, em janeiro de 2010. Encontrou-se 10,1\% de casos de violência sob forma de ameaças, $8,4 \%$ como provocação, $4,8 \%$ como intimidação e 5,7\% como assédio sexual. As ocorrências foram perpetradas contra mulheres. Os profissionais não consideram seu local de trabalho seguro e $81,2 \%$ não foram treinados para reconhecer e agir frente a situações de violência. Conclui-se que o desconhecimento de procedimentos obrigatórios e o fato do tema não ser discutido nem alertado aos profissionais pode ser o motivo da baixa incidência de violência em relação à bibliografia consultada. PALAVRAS-CHAVE: Violência; Pessoal de saúde; Trabalho.

\section{VIOLENCE AGAINST PRIMARY HEALTH CARE PROFESSIONALS: A STUDY IN THE INTERIOR OF THE BRAZILIAN AMAZON}

ABSTRACT: This exploratory-descriptive study aimed to identify episodes of violence against health care professionals of the Family Health Strategy in the interior of the state of Amazonas and how these professionals perceive the conditions of security and prevention of violence at work. A self-applied semi-structured questionnaire was given, adapted from the Survey of Violence in the Workplace for Health Care Workers, in January of 2010. It was found that $10,1 \%$ of cases of violence were in the form of threats, $8,4 \%$ as provocation, $4,8 \%$ as intimidation and $5,7 \%$ as sexual harassment. The events were perpetrated against women. The health professionals did not consider their workplaces secure and $81.2 \%$ had not been trained to recognize or react in situations of violence. It is concluded that lack of awareness of the obligatory procedures, the fact of the topic not being discussed and staff not being warned about it may be the reason for the low incidence of violence in relation to the bibliography consulted.

KEYWORDS: Violence; Health personnel; Work.

\section{VIOLENCIA CON PROFESIONALES DE LA ATENCIÓN BÁSICA: ESTUDIO EN EL INTERIOR DE LA AMAZONIA BRASILEÑA}

RESUMEN: Estudio exploratorio descriptivo cuyo objetivo fue identificar violencia con profesionales de la estrategia Salud da Familia del interior del Estado de Amazonas y su percepción acerca de las condiciones de seguridad y prevención de la violencia en el trabajo. Fue aplicado un cuestionario, autoaplicable, semi estructurado y adaptado del Survey of Violence in the Workplace for Health Care Workers, en enero de 2010. Fueron encontrados 10,1\% de casos de violencia en forma de amenazas, $8,4 \%$ como provocación, $4,8 \%$ como intimidación y $5,7 \%$ como asedio sexual. Las ocurrencias fueron perpetradas contra mujeres. Los profesionales no consideran su local de trabajo seguro y $81,2 \%$ no fueron entrenados para reconocer y actuar delante de situaciones de violencia. Se concluye que el desconocimiento de procedimientos obligatorios y el hecho del tema no ser discutido ni alertado a los profesionales puede ser el motivo de la baja incidencia de violencia en relación a la bibliografía consultada.

PALABRAS CLAVE: Violencia; Personal de salud; Trabajo.

*Pesquisa financiada pelo CNPq e realizada entre a Universidade Federal de Santa Catarina - UFSC e a Universidade Federal do Amazonas - UFAM.

${ }^{1}$ Psicóloga. Mestre em Saúde Coletiva. Psicóloga do Serviço de Atenção Psicológica da UFSC.

${ }^{2}$ Enfermeira. Doutora em Filosofia da Enfermagem. Professora do Programa de Pós-Graduação em Saúde Coletiva da UFSC.

${ }^{3}$ Cirurgião Dentista. Doutor em Efermagem Psiquiátrica. Vice-Coordenador e Professor do Departamento e do Programa de PósGraduação em Saúde Coletiva da UFSC. Editor Chefe do periódico Saúde \& Transformação Social.

${ }^{4}$ Enfermeira. Mestre em Saúde Coletiva. Doutoranda pelo Programa de Pós-Graduação em Saúde Coletiva da UFSC.

Autor correspondente:

Recebido: 31/01/2012

Beatriz Gomes Molinos Aprovado: 15/04/2012

Universidade Federal de Santa Catarina

Rua das Acácias, 121 - 88040-560 -Florianópolis-SC-Brasil

E-mail: beatriz@cfh.ufsc.br 


\section{INTRODUÇÃO}

A violência é considerada como

o uso intencional da força física ou do poder, real ou em ameaça, contra si próprio, contra outra pessoa ou contra um grupo ou comunidade, que possa resultar em, ou tenha alta probabilidade de resultar em morte, lesão, dano psicológico, problemas de desenvolvimento ou privação ${ }^{(1: 27)}$

Neste contexto, insere-se a violência no trabalho, que pode ser definida como qualquer ação voluntária de um indivíduo ou grupo contra outro indivíduo ou grupo, no ambiente de trabalho ou em seu entorno, tendo como consequência algum tipo de dano físico ou psíquico relacionado à segurança e saúde do trabalhador. Nestas ações, estão incluídas quaisquer formas de privação, infração de direitos trabalhistas e previdenciários ou qualquer negligência em relação às condições de trabalho ou omissão de cuidados ${ }^{(2)}$.

A violência contra profissionais de saúde pode acarretar na ocorrência de absenteísmo, licenças, rotatividade, ou mesmo a mudança de profissão devido a adoecimentos psíquicos, como depressão, ocorrência de sintomas psicossomáticos, desânimo, além de conflitos no relacionamento entre colegas ${ }^{(3)}$. Para as instituições há elevação de custos, dificuldade de contratar e/ou manter os profissionais, possibilidade de destruição de patrimônio e aumento de gastos com a saúde dos trabalhadores. Um estudo realizado em Portugal alerta para os riscos em relação ao sistema de saúde como um todo, em função da desumanização e da perda da qualidade dos serviços, com inevitáveis prejuízos à sociedade ${ }^{(4)}$.

Dados da violência contra trabalhadores de enfermagem no Canadá, Estados Unidos, Suécia e Inglater$\mathrm{ra}^{(5)}$ comprovam que, entre os trabalhadores da saúde, estes são mais vulneráveis. O maior índice de violência foi verificado no Canadá, atingindo $80,2 \%$ dos profissionais, seguidos da Suécia (29\%) e Inglaterra (71\%); na França, foram registrados índices de assédio moral de $9 \%$. Nos Estados Unidos, foram apurados elevados índices de assédio sexual, 71,9\% dos enfermeiros relataram ser vítimas, sendo $53,4 \%$ por pacientes e $25 \%$ de colegas médicos.

No Brasil, um estudo realizado em hospitais de pronto atendimento de Belo Horizonte-MG verificou que $85,3 \%$ dos médicos foram vítimas de, pelo menos, um episódio de violência no ano anterior ao pesquisado, sendo protagonizados, em sua maioria, por pacientes.
Segundo a pesquisa, metade desses profissionais já pensou em solicitar transferência de local de trabalho ou mesmo em abandoná-lo em função destes episó$\operatorname{dios}^{(6)}$. No Rio de Janeiro-RJ, 70,4\% dos trabalhadores das Unidades Locais de Saúde foram vítimas de algum tipo de violência, como agressões verbais $(65,5 \%)$, bulling (20\%), agressões físicas (7,3\%), assédio sexual $(3,6 \%)$ e por discriminação racial $(3,6 \%)^{(7)}$. Índices semelhantes foram verificados em Belo Horizonte-MG, com $68,9 \%$ de ocorrências contra os médicos ${ }^{(2)}$.

A violência, em todas as suas manifestações, é um grave e importante problema que estamos enfrentando, deixando de ser um fato exclusivamente policial para ser um problema social que afeta a todos ${ }^{(8)}$. A Organização Pan-Americana de Saúde destaca que o setor saúde constitui a encruzilhada para onde confluem todos os corolários da violência, pela pressão que suas vítimas exercem sobre os serviços de urgência, de atenção especializada, de reabilitação física, psicológica e de assistência social ${ }^{(9)}$.

Diante desta realidade há necessidade de conhecer e investigar situações de risco a que os profissionais da saúde estão submetidos, em diferentes regiões do país, para implementar políticas públicas que atendam às diversidades locais. O presente artigo propôs-se a identificar episódios de violência com profissionais da Estratégia de Saúde da Família (ESF) de quatro municípios do interior do Estado do Amazonas e a percepção dos trabalhadores quanto às condições de segurança e prevenção da violência no trabalho.

\section{MÉTODO}

Trata-se de uma pesquisa exploratória, descritiva, de abordagem quantitativa, realizada nos Municípios de Coari, Parintins, Manacapuru e São Gabriel da Cachoeira, todos do Estado do Amazonas. Esse é o segundo estado mais rico da Região Norte do Brasil e o mais extenso do país, respondendo por cerca de 1,8\% da população do Brasil e com densidade demográfica de 2,05 habitantes $/ \mathrm{km}^{2}$. Possui 62 municípios, dentre os quais apenas Parintins e Manaus possuem mais de 100 mil habitantes, sendo que este último responde por $53,9 \%$ da população amazonense ${ }^{(10)}$.

Os quatro municípios incluídos no estudo localizamse no interior do Amazonas e foram escolhidos pelas peculiaridades em termos de logística para o acesso. Coari é distante $363 \mathrm{~km}$ da capital Manaus e escolhido por se tratar do quarto município mais rico da Região Norte; apresenta uma população de 75.909 habitantes, sendo 
$65,39 \%$ urbana e $34,61 \%$ rural; seus indicadores sociais apontam para uma taxa de fecundidade de 6,74 filhos por mulher, $88,63 \%$ de alfabetização, Índice de Desenvolvimento Humano (IDH) de 0,627 e Produto Interno Bruto (PIB) per capita de $\mathrm{R} \$ 23.084,00^{(11)}$.

Parintins fez parte do estudo pela relevância entre os municípios interioranos e facilidade de acesso, mesmo distanciando-se $315 \mathrm{~km}$ de Manaus, e também em função de realizar o Festival Folclórico - considerado um dos principais patrimônios culturais da América Latina, atraindo turistas de todo o Brasile do mundo; a população estimada em 2009 era de 107.250 habitantes, com PIB per capita de $\mathrm{R} \$ 3.836,35^{(11)}$.

São Gabriel da Cachoeira foi incluído pela peculiaridade de ser o município com maior população indígena do país (96\% da população); localiza-se há $852 \mathrm{~km}$ da capital, em uma área de segurança nacional, dada a sua posição fronteiriça e estratégica no Sudeste Amazonense, com forte presença do exército em toda sua área. O município tem uma população de 37.300 habitantes, IDH de 0,673 e PIB per capita de R $\$ 4.607,00^{(11)}$.

Diferentemente dos municípios anteriores, cujo acesso a Manaus se dá exclusivamente por vias fluviais e aéreas, Manacapuru permite deslocamento à capital por via terrestre, localizando-se a $84 \mathrm{~km}$ desta. Sua população é de 85.144 habitantes, com IDH de 0,663 e um PIB per capita de $\mathrm{R} \$ 4.366,44^{(11)}$.

A população de referência deste estudo constituiu-se dos médicos, enfermeiros, cirurgiões dentistas, técnicos e auxiliares de enfermagem e de saúde bucal, e agentes comunitários de saúde de todas as equipes de Saúde da Família de zona urbana dos quatro municípios já indicados, com mais de um ano de implantação ${ }^{(11)} \mathrm{e} e m$ atividade no período de janeiro e fevereiro de 2010 nas cidades participantes do estudo. $\mathrm{O}$ instrumento utilizado para a coleta de dados foi um questionário semiestruturado adaptado do Survey of Violence in the Workplace for Health Care Workers ${ }^{(12)}$. Também foram levantadas características sociodemográficas e trabalhistas da população de referência, tais como idade, gênero, tempo de formação, local de trabalho, função, vínculo empregatício, tempo de trabalho e ocorrência de violência moral, psicológica ou física contra profissionais de saúde, ou presenciada em seu local de trabalho, nos últimos 12 meses.

O instrumento utilizado para a avaliação dos episódios de violência permitiu levantar informações sobre a prevalência de ofensas, gritos, xingamento, silêncio deliberado, postura agressiva, intimidação, comportamento hostil, extorsão, assédio sexual, discriminação racial, provocação e perseguição ${ }^{(13)}$. O instrumento também in- quiriu sobre a segurança no local de trabalho, a existência de treinamento dos profissionais para enfrentamento da violência e as políticas de prevenção e de atendimento das vítimas da violência, além da necessidade de afastamento do trabalho em função da violência sofrida.

Foram utilizados questionários autoaplicáveis e anônimos, entregues pelos pesquisadores a todos os profissionais das Unidades de Saúde da Família (USF), os quais foram instruídos a devolvê-los no dia seguinte, depositando-os em urna lacrada, sem identificação. Essa mesma orientação foi dada aos que não desejaram participar da pesquisa, entregando os questionários em branco. Os dados foram digitados em planilha de Excel por terceiros, havendo controle de qualidade por meio de dupla digitação e comparação com o banco de dados original de $10 \%$ dos questionários, escolhidos aleatoriamente. Para a análise estatística, utilizou-se o pacote estatístico Stata SE 9.0. O questionário entregue em branco foi contabilizado anteriormente à digitação.

Este estudo faz parte do Projeto "Saúde da Família no interior do Estado do Amazonas e a operacionalização dos princípios do SUS", fomentado pelo CNPq, através do Edital Universal 2009. Foram seguidos todos os procedimentos regulamentados na legislação brasileira sobre Pesquisa com Seres Humanos, sendo o projeto aprovado pelo Comitê de Ética em Pesquisa com Seres Humanos da UFSC, processo n.121/09 FR 259768.

\section{RESULTADOS}

Foram entrevistados 446 profissionais, sendo 80 de nível superior ( 9 médicos, 29 dentistas e 42 enfermeiros), 60 de nível médio (34 técnicos em enfermagem, 22 técnicos de saúde bucal e 4 auxiliares de saúde bucal) e 306 agentes comunitários de saúde (ACS), de nível fundamental. Entre os profissionais de nível superior, os enfermeiros eram maioria em três das quatro cidades que fizeram parte do estudo (Coari com 4,8\%, Parintins com 16,3\% e Manacapuru com 12\%), enquanto em São Gabriel da Cachoeira a maioria foi de dentistas (12\%). Em Manacapuru, os profissionais de nível médio foram maioria, sendo os técnicos em enfermagem 12,7\% destes. No Município de São Gabriel da Cachoeira, os auxiliares de saúde bucal foram a maioria, com um total de $8,1 \%$. Os ACS participaram em maior número quando comparados com os demais profissionais. Chamou atenção o reduzido número de médicos nas cidades de Coari e Manacapuru e a inexistência destes profissionais em Parintins e São Gabriel da Cachoeira (Tabela 1). 
Tabela 1 - Distribuição e escolaridade dos profissionais participantes do estudo sobre episódios de violência em municípios do interior do Amazonas. Florianópolis, 2010

\begin{tabular}{|c|c|c|c|c|c|c|c|c|c|c|}
\hline GRAUDEESCOLARIDADE & Coari & $\%$ & Parintins & $\%$ & Manacapuru & $\%$ & S.G.C.* & $\%$ & Total & $\%$ \\
\hline \multicolumn{11}{|c|}{ Nível superior } \\
\hline Enfermeiro & 6 & 4,8 & 8 & 16,3 & 18 & 12 & 10 & 8,1 & 42 & 9,4 \\
\hline Médico & 1 & 0,8 & - & - & 8 & 5,3 & - & - & 9 & 2,0 \\
\hline Dentista & 1 & 0,8 & 4 & 8,2 & 9 & 6 & 15 & 12,2 & 29 & 6,5 \\
\hline $\begin{array}{l}\text { Educação técnica profissio- } \\
\text { nalizante }\end{array}$ & 14 & 11,3 & 4 & 8,2 & 24 & 16 & 18 & 14,6 & 60 & 13,4 \\
\hline Nível fundamental (**ACS) & 102 & 82,3 & 33 & 67,3 & 91 & 60,7 & 80 & 65,0 & 306 & 68,6 \\
\hline Total & 124 & 100 & 49 & 100 & 150 & 100 & 123 & 100 & 446 & 100 \\
\hline
\end{tabular}

*S.G.C- São Gabriel da Cachoeira **ACS - Agente Comunitário de Saúde

A maioria dos profissionais da ESF das quatro cidades foram mulheres, com idade entre 19 e 39 anos, vínculo de trabalho celetista e com ensino fundamental, em função do elevado número de ACS. A maior parte dos profissionais de nível superior possuía até um ano de tempo de serviço sendo que destes, 9 eram médicos. Dos dentistas, $89,7 \%$ possuíam até 5 anos de serviço e $92,9 \%$ dos enfermeiros também tinham este mesmo tempo de serviço. Os técnicos, em sua maioria, atuavam na função entre 6 e 10 anos. Dos ACS, $29,4 \%$ possuíam até um ano de serviço e $53,9 \%$ entre 1 e 5 anos (Tabela 2).

Em relação aos episódios de violência que os profissionais da ESF sofreram, foram relatadas ameaças, intimidação, assédio sexual e provocação, sendo que $10,1 \%$ foram ameaçados enquanto exerciam suas atividades. É importante destacar que todas as ameaças foram contra mulheres, sendo $18,7 \%$ delas enfermeiras, médicas ou dentistas, $5 \%$ técnicas e $8,8 \%$ ACS. Das ameaças sofridas, $7,4 \%$ foram exercidas por colegas de trabalho e 6,3\% por pacientes. Os ACS foram os únicos profissionais agredidos tanto por colegas como por pacientes e acompanhantes (Tabela 3).

Das violências sofridas pelos profissionais de nível superior, o assédio sexual ocorreu em 11,2\%, e chama a atenção por terem ocorrido somente com os dentistas e perpetrados por pacientes, na Cidade de São Gabriel da Cachoeira. A prevalência para a intimidação foi de 7,5\% e todos os casos ocorreram com os enfermeiros, sendo realizadas por colegas de trabalho. A provocação e o assédio sexual foram as agressões apontadas, respectivamente, por $15 \%$ e $5 \%$ dos técnicos, e todas foram praticadas por pacientes. Entre os ACS, 10,1\% sofreram provocação e $6,9 \%$ intimidação, sendo que as agressões foram cometidas por colegas $(7,3 \%)$ ou por pacientes $(3,1 \%)$;
$1 \%$ necessitou se afastar do trabalho em virtude do episódio de violência relatado. Importante ressaltar que, entre os profissionais consultados, os ACS foram os que apresentaram a menor prevalência de violência, mesmo sendo em maior número entre os consultados (Tabela 4).

Quando consultados sobre a vulnerabilidade de seu ambiente de trabalho, $67 \%$ dos profissionais de nível superior afirmaram que o acesso ao local de trabalho é restrito a pacientes, acompanhantes e pessoas autorizadas. No entanto, $56,3 \%$ destes não consideraram o ambiente seguro, afirmando que a segurança podia melhorar. Chama atenção quando se constata que $81,2 \%$ dos profissionais informaram não ter recebido treinamento sobre segurança no trabalho e, dos que receberam, somente $12,2 \%$ sentiam-se preparados para responder adequadamente a situações de violência, enquanto $59,7 \%$ conheciam a possibilidade de suspender o trabalho quando se sentissem ameaçados. Fatores considerados situacionais e circunstanciais, como a movimentação de pessoas sem autorização nos locais de trabalho, podem gerar situações de vulnerabilidade e violência. Sobre a existência de programas de suporte às vítimas de violência, $77,5 \%$ dos profissionais de nível superior disseram desconhecer tal iniciativa. Para 92,5\% dos profissionais da ESF não havia informações sobre usuários da Unidade de Saúde com história prévia de violência.

Para $60 \%$ dos profissionais técnicos, seu ambiente de trabalho tinha acesso restrito a funcionários e pessoas autorizadas. No entanto, $70 \%$ deles não o consideraram seguro e $95 \%$ afirmaram que a condição de segurança de trabalho podia melhorar, sendo que $73,3 \%$ não conheciam a possibilidade de suspender seu trabalho quando sua segurança fosse ameaçada. Eles desconheciam a existência de programa ou política de 
prevenção da violência em seu ambiente de trabalho, e não tinham informações sobre usuários da Unidade de Saúde com história prévia de violência. Quando perguntado sobre a existência de programa de suporte às vítimas de violência, 93,3\% nada souberam informar.

Os ACS são os profissionais que na ESF desempenham o papel de articulador entre a sociedade e a equipe da ESF. Quando entrevistados sobre o treinamento para lidar com as situações de violência, $22,1 \%$ deles afirmaram ter tido treinamento e, destes, $9 \%$ sentiam-se preparados para lidar com estas situações, enquanto $63,7 \%$ desconheciam a possibilidade de suspender o trabalho quando sentissem sua segu- rança ameaçada. É importante destacar que 80,1\% desconheciam a existência de programa de suporte às vítimas de violência em sua Unidade de Trabalho e $99 \%$ responderam que não havia informações sobre usuários com história prévia de violência.

$\mathrm{Na}$ necessidade de chamar a polícia, caso tivessem sua segurança ameaçada no local de trabalho, $73,4 \%$ dos profissionais afirmaram ter essa permissão. A maioria dos profissionais, ou seja, 95,7\% que fizeram parte do estudo, não pensaram em abandonar ou solicitar transferência do local de trabalho em virtude de episódios de violência sofridos no trabalho, sendo que, para os profissionais de nível superior, este valor atingiu 100\%.

Tabela 2 - Perfil socioeconômico dos profissionais participantes do estudo sobre episódios de violência em municípios do interior do Amazonas. Florianópolis, 2010

\begin{tabular}{|c|c|c|}
\hline VARIÁVEIS & $\mathbf{N}$ & $\%$ \\
\hline \multicolumn{3}{|l|}{ Escolaridade } \\
\hline Ensino superior & 80 & 18,0 \\
\hline Educação profissionalizante & 60 & 13,4 \\
\hline Ensino fundamental & 306 & 68,6 \\
\hline \multicolumn{3}{|l|}{ Faixa etária (anos) } \\
\hline $19-29$ & 230 & 51,6 \\
\hline $30-39$ & 176 & 39,5 \\
\hline$>40$ & 40 & 8,9 \\
\hline \multicolumn{3}{|l|}{ Sexo } \\
\hline Feminino & 339 & 76,0 \\
\hline Masculino & 107 & 24,0 \\
\hline \multicolumn{3}{|l|}{ Vínculo empregarício } \\
\hline Concursado & 62 & 13,9 \\
\hline Celetista & 351 & 78,7 \\
\hline Prestador de serviço & 33 & 7,4 \\
\hline \multicolumn{3}{|c|}{ Tempo de serviço (esc./tempo em anos) } \\
\hline \multicolumn{3}{|l|}{ Nível Superior } \\
\hline Até 1 & 42 & 51,5 \\
\hline 1 a 5 & 32 & 40,0 \\
\hline 6 a 10 & 03 & 3,7 \\
\hline$>10$ & 03 & 3,7 \\
\hline \multicolumn{3}{|l|}{ Nível Técnico } \\
\hline Até 1 & 16 & 26,7 \\
\hline 1 a 5 & 16 & 26,7 \\
\hline 6 a 10 & 25 & 41,7 \\
\hline$>10$ & 03 & 5,0 \\
\hline \multicolumn{3}{|l|}{ Nível Fundamental } \\
\hline Até 1 & 110 & 35,9 \\
\hline 1 a 5 & 165 & 53,9 \\
\hline 6 a 10 & 29 & 9,5 \\
\hline$>10$ & 02 & 0,7 \\
\hline Total & 446 & 100,0 \\
\hline
\end{tabular}


Tabela 3 - Distribuição de profissionais agredidos segundo escolaridade e agressor entre participantes do estudo sobre episódios de violência em municípios do interior do Amazonas. Florianópolis, 2010

\begin{tabular}{|c|c|c|c|c|c|c|c|c|}
\hline $\begin{array}{l}\text { Profissionais por ní- } \\
\text { vel de escolaridade }\end{array}$ & $\begin{array}{l}\text { Não sofreram } \\
\text { agressão }\end{array}$ & $\%$ & $\begin{array}{l}\text { Agredidos } \\
\text { por Paciente }\end{array}$ & $\%$ & $\begin{array}{l}\text { Agredidos por } \\
\text { Acompanhante }\end{array}$ & $\%$ & $\begin{array}{l}\text { Agredidos } \\
\text { por Colega }\end{array}$ & $\%$ \\
\hline Superior & 53 & 74,6 & 9 & 12,7 & - & - & 9 & 12,7 \\
\hline $\begin{array}{l}\text { Educação técnica/ } \\
\text { profissionalizante }\end{array}$ & 57 & 95,0 & 3 & 5,0 & - & - & - & - \\
\hline Fundamental(*ACS) & 252 & 88,4 & 3 & 1,0 & $J$ & 1,05 & 27 & 9,5 \\
\hline Total & 362 & 86,0 & 15 & 6,3 & 3 & 0,3 & 36 & 7,4 \\
\hline
\end{tabular}

*ACS - Agente Comunitário de Saúde

Tabela 4 - Distribuição de profissionais segundo escolaridade e tipo de agressão sofrida entre participantes do estudo sobre episódios de violência em municípios do interior do Amazonas. Florianópolis, 2010

\begin{tabular}{|c|c|c|c|c|c|c|c|c|c|c|}
\hline $\begin{array}{l}\text { Profissionais } \\
\text { por nível de } \\
\text { escolaridade }\end{array}$ & $\begin{array}{c}\text { Não } \\
\text { respondeu }\end{array}$ & $\%$ & Intimidação & $\%$ & $\begin{array}{c}\text { Assédio } \\
\text { sexual }\end{array}$ & $\%$ & Provocação & $\%$ & $\begin{array}{l}\text { Não sofreu } \\
\text { agressão }\end{array}$ & $\%$ \\
\hline Superior & 6 & 7,5 & 6 & 7,5 & 9 & 11,2 & - & - & 59 & 73,7 \\
\hline $\begin{array}{l}\text { E d u c a ç ã o } \\
\text { técnica/ } \\
\text { profissiona- } \\
\text { lizante }\end{array}$ & - & - & - & - & 3 & 5,0 & 9 & 15,0 & 48 & 80,0 \\
\hline $\begin{array}{l}\text { Fundamental } \\
\left({ }^{*} \text { ACS }\right)\end{array}$ & 6 & 2,0 & 21 & 6,9 & 3 & 1,0 & 31 & 10,1 & 245 & 80,1 \\
\hline Total & 12 & 3,1 & 27 & 4,8 & 15 & 5,7 & 40 & 8,4 & 352 & 78,0 \\
\hline
\end{tabular}

* ACS - Agente Comunitário de Saúde

\section{DISCUSSÃO}

Durante a realização deste estudo, foi constatado que em Parintis e São Gabriel da Cachoeira não havia médicos disponíveis para atendimento e em Coari havia apenas um. Parintins, a cidade mais populosa, com o dobro da população de São Gabriel da Cachoeira, por exemplo, era a que menos possuía ACS disponíveis; não havia médico e apenas quatro cirurgiões dentistas.

Apenas 13,9\% dos profissionais eram contratados por concursos públicos. Essa realidade justifica a rotatividade de profissionais, onde a maior parte possuía até cinco anos de atividade no serviço. A rotatividade, de acordo com alguns autores, inviabiliza a possibilidade de atingir a integralidade das ações da saúde ${ }^{(14)}$.

Em relação à violência contra os profissionais, ressaltamos que nenhum relatou ter sido vítima de violência física, porém houve incidência de violência psicológica, $10,1 \%$ foram ameaçados, $8,4 \%$ sofreram provocação e $4,8 \%$ intimidação. A violência psicológica tem como propósito degradar ou controlar ações, as formas de agir e de tomar decisões por meio de manipulação, intimidação, ameaça, humilhação ${ }^{(15)}$.

Caracterizada como um tipo de violência psicológica, a ameaça é uma forma de violência que, por não deixar marcas visíveis, nem sempre é fácil de se detectar. Às vezes ela é sutil, mas, em geral, é explicitada verbalmente. Suas marcas no psiquismo podem ser tão ou mais severas do que alguns tipos de violência física. A ansiedade decorrente dessas situações pode impedir que o profissional desempenhe suas tarefas de forma satisfatória ${ }^{(4,10)}$.

Os outros tipos de violência psicológica verificados no estudo foram a provocação e a intimidação. Provocar, segundo o dicionário ${ }^{(16: 2322)}$ é "forçar (alguém) a responder a um desafio; desafiar; dizer desaforos a; insultar; fazer perder a calma; irritar, perturbar". Por sua vez, intimidar, segundo o mesmo dicionário, é "provocar ou sentir apreensão, receio ou temor; amedrontar (-se)". Provocação e intimidação são relatadas em estudo sobre disputas de poder, ou exercidas em categorias funcionais com diferentes hierarquias $^{(3)}$. Compreendidas como formas de assédio moral no trabalho podem estar associadas aos casos de violência relatados por enfermeiros e ACS como sendo praticados por colegas de trabalho, com intuito de desafiar/amedrontar, e sustentados por relações assimétricas e desiguais.

Embora a população estudada tenha sido composta 
por $76 \%$ de mulheres, destaca-se que os profissionais ameaçados e que sofreram mais violência são mulheres. Estudo realizado sobre a violência contra os trabalhadores de enfermagem em São Paulo-SP, afirma que as profissionais da saúde do sexo feminino sofrem ameaças em número superior à população em geral. A maior parte dos casos foi perpetrada por homens colegas de trabalho $(39,7 \%)$ e por chefia $(23,5 \%)$. O mesmo estudo revela que maioria das profissionais não denunciou o fato, com medo de represálias ${ }^{(3)}$.

Além da ameaça, o tipo de violência relatado por mulheres, em todas as categorias profissionais, foi o assédio sexual provocado por pacientes. $\mathrm{O}$ assédio sexual é conceituado como qualquer ato que provoque constrangimento e exercido por palavras, gestos ou com emprego de violência, prevalecendo-se de relação de confiança, empregatícia ou de autoridade, com intento de obter vantagem sexual ${ }^{(17)}$. O fato do assédio ter sido perpetrado por pacientes parece estar vinculado à cultura de dominação masculina. Ainda existe, nas relações de trabalho, a ideologia de que mulheres não podem ocupar certas posições e cargos, e quando isso ocorre, os homens se acham autorizados a exercer o poder de constranger e dissuadir a permanência das mesmas em seus postos ${ }^{(18)}$.

O trabalho dos profissionais da ESF está baseado no vínculo de proximidade com os usuários do serviço e a comunidade onde está inserido. Cria-se, desta forma, um ambiente propício para que o profissional se envolva mais na problemática e condição de saúde da população. Por outro lado, esta ação tende a gerar aproximações de risco, tornando estes profissionais vulneráveis à violência ${ }^{(19)}$. Apesar de estudos afirmarem que os profissionais da saúde se encontram entre as categorias de alto risco de vulnerabilidade em situações de violência, os dados coletados nas quatro cidades do Amazonas não confirmam os altos índices registrados em outras regiões ${ }^{(12,18)}$.

Podemos considerar esses resultados como um fato positivo e que os profissionais dessas cidades trabalham em ambiente pouco violento ou questionar o que seria considerado violência para os profissionais consultados no estudo. Em nosso país, muitas ações violentas são tomadas de forma naturalizada ${ }^{(20)}$. As relações entre os indivíduos, em nossa sociedade, têm caracterizações de poder tão enraizadas que nem sempre são percebidas como tal pelo agressor nem pela vítima. Assim, a aceitação ocorre com alguma naturalidade, e as ações violentas são percebidas como adequadas e, de alguma forma, até mesmo esperadas.
Nossa sociedade desigual possibilita que certos atos violentos se instituam, pois quem se submete não dispõe de condições para pensar sobre a violência e sobre si mesmo ${ }^{(21)}$. Muitas vezes sutil, insensível e invisível, a violência é exercida por vias simbólicas da comunicação, revelando formas de relação social decorrentes de estilos de vida onde o que está estabelecido não é pensado, ou questionado, mas apenas cumprido.

No estudo sobre as repercussões da violência na saúde mental de trabalhadores do Programa Saúde da Família, autores concluem que os trabalhadores desenvolvem estratégias para se proteger e diminuir a situação de vulnerabilidade. No estudo, as autoras afirmam que o convívio direto com os usuários provoca impacto sobre os trabalhadores em função da precariedade de situação de vida dos profissionais, ou por se sentirem acuados ao presenciar situações de violência, ou ainda desprotegidos por estar na casa dos usuários ou em locais externos à Unidade de Saúde. É por essas razões que, principalmente os ACS estabeleceriam estratégias de defesa individuais ou coletivas, o que permite administrar situações de risco a partir de redes de proteção e solidariedade da comunidade ${ }^{(3)}$.

Em estudo sobre a violência psicológica na prática profissional da enfermeira, as autoras ressaltam a importância de dar visibilidade e esse tipo de violência, com o propósito de denunciar abusos de poder e discriminação, e assim evitar a banalização da injustiça, pois as investigações mostram que abusos verbais, intimidações e assédio moral são mais frequentes do que agressões físicas ${ }^{(22)}$.

Outro fator relevante observado nos dados deste estudo foi o fato da maior parte dos profissionais vítimas de violência não se afastar do trabalho. A baixa incidência de índices de violência relatada pelos profissionais pesquisados, em relação à bibliografia existente, poderia levar a se inferir que a percepção de ambiente de trabalho é de segurança. Porém, isto não foi o constatado. A maior parte dos profissionais não considera seus locais de trabalho seguros, sendo que $60 \%$ afirmaram que as condições de segurança podiam melhorar.

Esta sensação de insegurança pode estar vinculada a fatores externos, como a localização em que estão inseridos os serviços de saúde ou, ainda, condição da cidade como um todo, em função do aumento da violência e divulgação da mesma no país, nos últimos $\operatorname{anos}^{(23)}$, o que contribui para sua banalização.

Entre os projetos propostos pelo Ministério da Saúde (MS) em 2001 para a promoção de saúde e cuidado com o trabalhador, há indicação de estratégias preven- 
tivas que se dariam através de ações e planejamento com vistas a proporcionar melhor qualidade de $\operatorname{vida}^{(10)}$.

No presente estudo, foi constatado que a maior parte dos trabalhadores não se submeteu a nenhum programa ou política de prevenção contra a violência. Constatou-se, inclusive, que estes não receberam instruções para seu cuidado próprio em caso de violência, além de não estarem treinados para detectar e auxiliar na construção de redes de proteção dos usuários. Esta situação se agrava ainda mais quando todos os profissionais técnicos submetidos ao treinamento não se consideravam preparados para lidar com situações de violência e apenas $9 \%$ dos ACS que realizaram o treinamento se sentiam aptos.

Como se conclui, o treinamento preconizado pelo MS para atender as políticas de prevenção e para denúncia de violência não se efetiva a contento para a população pesquisada. A alta rotatividade de algumas categorias e a forma de contrato trabalhista, em sua maioria sem realização de concurso publico, pode ser um dos motivos. Tão ou mais grave que o dado da não ocorrência de treinamento é o índice de insatisfação quanto ao efetivo auxilio do mesmo para o enfrentamento de situações violentas. Assim, quando ele acontece, não corresponde às expectativas e nem proporciona aumento de capacidade dos trabalhadores em se proteger ${ }^{(23)}$. Em sua maioria, os profissionais consultados não possuíam conhecimento de seus direitos trabalhistas; eles desconheciam o fato de ter o direito de se afastar do trabalho quando se sentissem ameaçados e mesmo exigir ambiente seguro para realização de suas atividades.

A discussão e preocupação da comunidade científica sobre a violência propiciaram ações governamentais de incentivo a estudos sobre o tema. A Portaria n.737/GM, de 16 de maio de 2001, estabeleceu diretrizes para promoção de saúde e prevenção de agravos externos ${ }^{(24)}$. A Portaria n. 936/GM/MS de 18 de maio de 2004 criou normas de estruturação de uma Rede Nacional de Prevenção da Violência e Promoção de Saúde cujas atribuições são identificar e apoiar estudos, pesquisas e ações acadêmicas, além de qualificar a gestão do Sistema Único de Saúde para o trabalho de prevenção de violência e promoção de saúde ${ }^{(25)}$. Estas portarias ressaltam a importância do trabalho de prevenção da violência, ao auxiliar os profissionais da saúde em sua capacidade para detectar e registrar os eventos, a fim de melhorar os serviços junto à população em risco. É de supor que o desconhecimento desses procedimentos obrigatórios deve contribuir para a baixa incidência de registro da violência. $\mathrm{O}$ agravante disso é que o tema violência não é discutido nem alertado para que os profissionais o considerem como dado relevante de saúde em relação à população atendida e aos colegas de trabalho.

\section{CONSIDERAÇÕES FINAIS}

A população consultada, em sua maioria, era do sexo feminino. Todas as ocorrências de violências relatadas foram de queixas de mulheres e perpetradas por pacientes, acompanhantes e, principalmente, por colegas de trabalho. As ameaças, intimidações e provocações, como formas de violência psicológica, podem estar associadas à disputas de poder e/ou assédio moral.

$\mathrm{O}$ assédio sexual foi evidenciado em todas as categorias profissionais e incitado por pacientes, o que possibilita sustentar a hipótese da influência de aspectos culturais que enfatizam um lugar de submissão e de objeto sexual atribuídos às mulheres.

A implantação da política pública de prevenção à violência tem sido insuficiente o que, provavelmente, pode estar interferindo nos índices de percepção de ocorrência de violência. Os profissionais, em sua maioria, não foram treinados e os que o foram não se consideram aptos a responder de forma satisfatória a atos violentos. A maior parte dos profissionais considera que o ambiente de trabalho pode melhorar em relação à segurança. O programa de assistência à vítima de violência em sua unidade é desconhecido pela maioria da amostra consultada, o que contribui para a invisibilidade dos diferentes tipos de violência. Foram reveladas falhas na política de prevenção e na capacitação para detectar, registrar, defender-se e prevenir a violência.

\section{REFERÊNCIAS}

1. Organização Mundial da Saúde (OMS). Relatório Mundial sobre Violência e Saúde. Genebra; [Internet] 2002. [acesso em 23 fev 2010] Disponível: http://www. opas.org.br/cedoc/hpp/ml03/0329.pdf

2. Campos AS. Violência no trabalho em saúde: um tema para cooperação internacional em recursos humanos para a saúde. Reciis. 2010;4(1):86-92

3. Lancman S, Ghirardi M, Castro E, Tuacek T. Repercussões da violência na saúde mental de trabalhadores do Programa Saúde da Família. Rev. Saúde Pública. 2009;43(4):682-8. 
4. Ferrino $\mathrm{P}$, Antunes AR, Biscaia A, Conceição C, Fronteira I, Craveiro I, et al. Violência no local de trabalho no sector da saúde: estudos de caso portugueses. Lisboa. Associação para o Desenvolvimento e Cooperação Garcia D’Orta. [Internet] 2002. Relatório Final [acesso em 15 Set 2010].Disponível: http://www. ago.pt/attachments/060_vt_relatorio.pdf

5. Contrera-Moreno L, Contrera-Moreno MI. Violência no trabalho em enfermagem: um novo risco ocupacional. Rev Bras Enferm. [Internet] 2004;57(6) [acesso 14 aug 2010]. Disponível: http://www. scielo.br/scielo.php?script=sci_arttext\&pid=S0034$71672004000600024 \& \operatorname{lng}=$ en\&nrm=iso

6. Santos Junior EA, Dias EC. Médicos vítimas da violência no trabalho em unidades de pronto atendimento. Cad. saude colet. 2005;13(3):705-22.

7. Palacios M. Violência no ambiente de trabalho no setor saúde da cidade do Rio de Janeiro: trabalhadores da saúde vítimas e algozes. Cienc. saude colet. 2003;8(2):214.

8. Baierl LF, Almendra CAC. A dinâmica perversa do medo e da violência urbana. Revista serviço Soc. Soc. 2002;(70):59-74.

9. Organizacion Panamericana de La Salud (OPAS). Violencia y salud. Washington, [Internet] 1993. [acesso 20 ago 2010]. Disponível: http://mayores.pre.cti.csic.es/ documentos/documentos/oms-informeviolencia-01.pdf

10. Brasil. Saúde do Trabalhador /Ministério da Saúde, Departamento de Atenção Básica, Departamento de Ações Programáticas e Estratégicas, Área Técnica de Saúde do Trabalhador. Brasília. Ministério da Saúde. [Internet] 2001. Caderno5. [acesso em 20 jul 2010]. Disponível: http://www.saude.sc.gov. br/saudetrabalhador/Caderno\%20ST\%20-\%20 Legisla\%E7\%E3o.pdf

11. Brasil, Ministério do Planejamentos Instituto Brasileiro de Geografia e Estatística (IBGE).[Internet] [acesso em 13 set 2011]. Disponível: www.ibge.gov.br

12. American Federation of State, County and Municipal Mployees. AFSCME. Survey of violence in the workplace for healthcare workers (Appendix D). In: Preventing workplace violence. Washington, DC, AFSCME[Internet] 1998. [acesso em 9 jan 2009]. Disponível: http://www.afscme.org/health/violad.htm

13. Chappell D, Di Martino V. Violence at the work. International Labour Office, Geneva; 2006.
14. Carvalho A, Pereira C, Gusberti R, Pereira S, Santos E. A percepção dos profissionais de saúde sobre o processo de trabalho do agente comunitário de saúde. In: Buchele F, Coelho E. A formação em saúde da família. Florianópolis: 2010. p.191-203

15. Minayo MCS. Violência e saúde. Rio de Janeiro: Fiocruz;2001.

16. Houaiss A, Villar M. Dicionário Houaiss de língua portuguesa. Rio de Janeiro: Objetiva; 2001.

17. Diniz MH. Dicionário jurídico. São Paulo: Saraiva;1998.

18. Lopes AA, Pontes AFR, Oliveira Junior IM. Assédio sexual nas relações do trabalho. Brasília: Consulex; 2001.

19. Pires RM. Projeto de Pesquisa aprovado pelo CNPq (CoSAU/CGSAU/DABS) sob o protocolo 470165/20081 (Edital MCT/CNPq 14/2008 - Universal/Edital MCT/CNPq 14/2008 - Universal - FaixaC): Saúde da Família no interior do Estado do Amazonas e a operacionalização dos princípios do SUS; 2008.

20. Chaui M. Ética e violência. Teoria e Debate. 1998;11(39):32-41.

21. Bordieu P. A dominação masculina. Rio de Janeiro: Bertrand Brasil; 2003.

22. Barbosa R, Labronici ML, Sarquis LMM, Mantovani MF. Violência psicológica na prática profissional da enfermeira. Rev Esc Enferm USP. 2011;45(1):26-32.

23. Lopes MJ, Paixão DV (org). Saúde da família: histórias, práticas e caminhos. Porto Alegre: UFRGS; 2007.

24. Brasil.Ministério da Saúde. Portaria GM no 737, de 16 de maio de 2001. Dispõe sobre a Política Nacional de Redução da Morbimortalidade por Acidentes e Violências. Diário Oficial da União, Brasília, 18 maio 2001. Seção 1.

25. Brasil. Ministério da Saúde. Portaria n. 936/GM, em 19 de maio de 2004. Dispõe sobre a estruturação da Rede Nacional de Prevenção da Violência e Promoção da Saúde e a Implantação e Implementação de Núcleos de Prevenção à Violência em Estados e Municípios. [Internet]. 2004. [acesso em 20 jul 2010]. Disponível: http://bvsms.saude.gov.br/bvs/saudelegis/gm/2004/ prt0936_19_05_2004.html 